\title{
Articulation of English Consonants, Vowels and Diphthongs by Pashto Speakers in Khyber Pakhtunkhwa, Pakistan
}

\author{
Afzal Khan ${ }^{1}$, Wasima Shehzad ${ }^{2} \&$ Inayat Ullah $^{3}$ \\ ${ }^{1}$ Department of Humanities, Faculty of Social sciences, Air University, Islamabad, Pakistan \\ ${ }^{2}$ Fulbright \& British Alumna, Dean, Faculty of Social Sciences, Air University, Islamabad, Pakistan \\ ${ }^{3}$ Assistant Professor, Department of Humanities, Faculty of Social Sciences, Air University, Islamabad, Pakistan \\ Correspondence: Afzal Khan, Department of Humanities, Faculty of Social sciences, Air University, Islamabad, \\ Pakistan. E-mail: afzalenghu@gmail.com; Afzal.khan@mail.au.edu.pk; wasima@mail.au.edu.pk; \\ wasima.shehzad@yahoo.com; inayat_ktk@yahoo.com; inayatullah@mail.au.edu.pk
}

Received: April 27, 2017 Accepted: May 18, 2017 Online Published: July 24, 2017

doi:10.5539/ijel.v7n5p19 URL: http://doi.org/10.5539/ijel.v7n5p19

\begin{abstract}
This paper aims to examine the articulation of English consonants, vowels and diphthongs by Pashto Speakers in Khyber Pakhtunkhwa, Pakistan, and explores the problems they face in their English articulation due to the influence of mother tongue. A detailed experiment has been carried out to analyze the articulatory properties of / / //ठ/Ir: /, /I/ and /er: / sounds spoken by Pashto speakers in Pakistan. The research reveals that Pashtun speakers of English language have a distinct pronunciation pattern of $/ \theta /$ and $/ \delta /$ sounds. This research provides a scientific justification to establish Pashto English as an independent deviant variety of RP Standard English Language. Based on the findings of the data collected from the recordings of 50 participants, it was concluded that thickness is low and frequencies of formants are considerably low as compared to RP sounds. In this regard, consonant phonemes of $/ \theta /$ and $/ ð /$ sounds articulated by Pashto speakers are dissimilar to their Standard English (RP). They are produced as "Dental Plosives" instead of "Dental Fricatives". The participants face great difficulty in pronouncing these English dental fricatives $/ \delta /, / \Theta /$ sounds, and they also face insurmountable problems in the regular plural forms. In relation to vowels and diphthongs in English language, major problems largely appeared in misunderstanding between /r:/, /I/ and /er:/ sound production. The results of this study shall provide assistance to English language teachers and learners in teaching and learning English Language, especially in teaching and learning English pronunciation. It has been ascertained that special consideration should be given to these problematic consonants, vowels and diphthongs in order to avoid misunderstandings/confusion on the part of the listener.
\end{abstract}

Keywords: Articulation, consonants, vowels, diphthongs, Pashto Speakers in Khyber, Pakhtunkhwa-Pakistan

\section{Introduction}

Pashto in Pakistan is spoken in Khyber Pakhtunkhwa Province, including Swat and Kaghan valley. Pashto is also spoken in the eastern and southern regions of Afghanistan, where it is the national language. Pashto is spoken by 9,585,000 speakers in Pakistan which is $8.47 \%$ of the total population according to the 1993 census estimation; 100,000 people speak Pashto in United Arab Emirates as recorded in the 1986 census; and 14,161 Pashto native speakers reside in India, noted in 1994 census. All Pashto speakers in Pakistan were estimated at $13.2 \%$ of the total population, according to 1981 Census. Pashto has many regional dialects in Pakistan, such as Kohati, and Khattak dialects. Yusufzai dialect is also known as Peshawari; Afridi; Mohmandi; Shinwari; and Shilmani. The major dialect of Khattaks, also known as Kohati and Kandahari, is considered as a soft dialect. The Yusufzai one is known as a hard dialect or the literary dialect, mostly practiced in schools and media in Khyber Pakhtunkhwa and its adjacent tribal regions in Pakistan (Baart, 2001).

Pashto is an ancient language and its script is written in Perso-Arabic. Pashto vocabulary contains words mostly borrowed from Ossete, Sanskrit, Hindi, Persian, Urdu and some other regional and local languages of Pakistan. It has also absorbed words from Indo-Aryan languages. Pashto Language is regarded to be in close similarity with Persian language but there exists certain contradictory features in Pashto Language that do not exist in Persian. For example, in Pashto, there are some consonants and vowels which are not present in Persian such as retroflex 
oral stops, retroflex flap, retroflex nasal and retroflex fricatives. Moreover, in Persian language, gender and noun case is not found. Noun is there only for categories of definiteness and number but in Pashto language it does exist. Stress and intonation pattern is also different between Persian and Pashto. In Pashto, the strong stress is placed not on the last syllable like Persian, but can vary in different syllables. This liberty plays significant grammatical function in Pashto and is practiced to give different meanings to similar words.

All ESL (English as a Second Language) or EFL (English as a Foreign Language) learners, whose first language is any Asian language, tend to demonstrate phonetic errors in their speech sound creation (Flege, 1989; Flege \& Davidian, 1985; Pittam \& Ingram, 1992; Tarone, 1980; Wang, 1983; Yang, 1996; Yang, 2001). English speakers of Pashto foundation have idiosyncratic features as far as the production of English sounds is concerned. In this way, this research concentrates on the segmental phonemes i-e consonants, vowels and diphthongs of the English language. Non-native speakers with quite different speech sounds confront different issues, when learning English language. For Pashto English speakers, there are certain English consonants, vowels and diphthongs that are generally troublesome in terms of articulation. For example, a number of them go for substitutions /th/ in addition to $/ \mathrm{t} /$ for interdental fricatives $/ \mathrm{d} /, / \mathrm{\theta} /$. So, they stray from real RP Standard English and face extraordinary troubles in the articulation of $/ \mathrm{\theta} /$ and $/ \mathrm{d} /$ sounds.

Besides English dental fricatives / $\Theta$ / and / $\circlearrowright$ / sounds, Pashto speakers face extreme problems in the articulation of the $/ \mathrm{s} /, / \mathrm{z} /$, and / $\mathrm{Iz} /$ sounds. Regarding vowels, English language learners of Pashto background are not able to differentiate between the vowel contrasts. In this connection, diphthongs are also commonly found mispronounced by Pashto speakers as well. In case of learning a foreign or second language by virtue of non-native speakers, the transfer of first language or L1 phonological topographies render a countless impact on L2 acquisition (Lado, 1964). In the same way, Pashto language exhibits a great impact in the articulation of the learners' production of English speech sounds. Therefore, various articulatory supra-segmental features of Pashto English speakers are closely linked to Pashto language. In this regard, these acquired supra-segmental articulatory features typically follow some systematic patterns, rather than happening accidentally. This study, therefore, intends to identify the articulatory problems in consonants, vowels and diphthongs by the Pashto speakers of Khyber Pakhtunkhwa and provides guidance for teachers and learners of English language.

\section{Literature Review}

Schmidt (1977) and Menyuk (1968) discussed that dental fricatives / $/$ and /e/ of English language are the latest language resonances that even local speakers acquire later in their linguistic developmental stage and commonly replace them by nearly additional speech sounds. It illuminates why the non-native speakers of English language always face problems in the articulation of these two consonants. One of the obvious problems faced by a large number of non-native speakers during English speech production is the sounds that lack in the target language that ultimately lead towards inaccurate speech sounds (Chang, 2000), such as interdental fricative /ठ/, /ब/.

Pashto language does not have these dental fricative sounds, so these resonances remain articulated like corresponding labial and dental stops of $/ \mathrm{th} /, / \mathrm{t} / \mathrm{and} / \mathrm{d} /$ found in Pashto, similar to the dental stops constituted in regional languages and Southern Irish English Davenport (Hannahs, 1998). Probably Pashto speakers perceive these resonances as stops; however, that requires further research to authenticate.

Elkhair (2014) investigated the problems in English articulation experienced by learners, whose first language was Sudanese Spoken Arabic. The findings of the study revealed that Sudanese Speakers of English, whose language background was Sudanese Spoken Arabic, faced problems with the articulation of English vowels that showed more than one way of articulation in addition to the consonant contrasts such as, $/ \mathrm{z} /$ and $/ \delta /, / \mathrm{s} /$ and $/ \theta /$, $/ \mathrm{b} /$ and $/ \mathrm{p} /, / \mathrm{g} /$ and $/ \mathrm{t} / \mathrm{s}$. Based on these findings, the researcher concluded that the basic factors such as first language interference in terms of the differences in the sound system in the two languages lead to inconsistency of English sounds and finally militate against Sudanese Students of English (SSEs) competence in their articulation.

Elmahdi \& Khan (2015) investigated the difficulties of English pronunciation faced by Saudi secondary school learners when articulating English consonants. The results demonstrated that a large number of participants inadvertently insert a vowel sound in English syllable to break up the consonant clusters. This study provides some valuable pedagogical implications to prevent and cure English pronunciation problems.

$\mathrm{Lu}$ (2008) suggested that speakers of different languages of the world, such as Chinese, take these phonemes /s, z/ $/ \mathrm{t}, \mathrm{d} /$, or /f, v/ as substitutions aimed at RP dental fricatives / $/$ / and / $/ \mathrm{e}$. Similarly, English language noun plural forms function very different from noun plural form of the construction in Pashto language. For instance, $/ \mathrm{t} / \mathrm{in}$ Pashto is used in the articulation of "thanks" instead of /e/. Plural forms of English language also generate hitches for Pashto speakers morphologically (Liu et al., 2006). However, no substantial research work has been carried out 
into the influence to see the phonological supra-segmental topographies of English noun plural forms by Pashto speakers.

Chang (2000) pointed out that the articulation of English RP diphthong, especially /eI/ by Chinese learners, demonstrated that the instant phonetic background influences the accurateness level of the diction of /er/ sound of English Language. She also determined that inclusive Chinese learners come across difficulties in the pronunciation of diphthong /er/ sound in addition to certain post-vocalic consonants. These phonemes set up the main substance of difficulties for Chinese English Language learners.

The basic consideration of phonetics and phonology, concerning English language, is crucial for those who need to surpass and be familiar with the philosophies regarding the accurate pronunciation of English speech sounds. Aimed at that reason, it is crucial to acquire English precise pronunciation by means of phonemes i.e., appropriate speech production as a substitute of only understanding alphabetic letters, owing to the tremendously perplexing nature of English spelling (Roach, 2000).

Yang (2001) conducted experimental study about English consonants, vowels and diphthongs used by Mandarin speakers. The researcher revealed that the auditory aspects of the production of these resonances in the articulation of vowels are scarcely acoustically varied as compared to American Native speakers' production (Yang et al., 2001). Wang (1997) directed an investigation on the subsequent vowels of English linguistic by Non-native

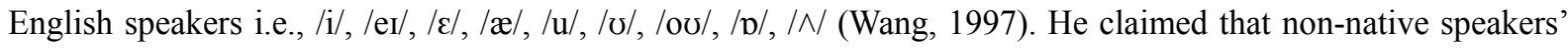
production of English vowels is going to be further comprehensible than those nonnative speakers that do not have superficial complements.

Therefore, this study aims to explore the pronunciation of English consonants, vowels and diphthongs by Pashto speakers in Khyber Pakhtunkhwa, Pakistan. Pashto speakers articulate English dental fricatives /ठ/, /ө/, incorrectly and are thus found confused despite pronouncing English vowels, diphthongs and noun plural form.

\section{Methodology}

\subsection{Subject}

Fifty participants were randomly selected from undergraduate classrooms as sample for population of non-native speakers in Khyber Pakhtunkhwa, Pakistan. They were from Government Post Graduate Jehanzeb College at Saidu in Sharif Swat, Government Degree College at Matta in Swat, Government Degree College at Madyan in Swat, Swat Public School and College, and Quaid-e- Azam Public School and College at Matta in Swat. Ten participants were selected from each college. All the participants were enrolled in these institutions to learn English language since their primary level of education, and now their present English proficiency level was that of the college level English, which is an essential prerequisite for university enrollments in Pakistan. Normally, they do not have foreign education background; therefore, their main learning of English language mostly takes place inside the classroom. As a result, their imperfect acquaintance with English language is commonplace.

\subsection{Assessment Material}

The following extract is a general analytical text, which covers the comprehensive catalogue of English speech sounds RP (Received Pronunciation).

If you're going shopping, John, his mother asked him, there is something important and his father was ill to bring them, will you please get me these few things? Though the weather remains harsh, and John's mother worried about these items, if it rains for long she would not be able to cook. She looked at John desperately. John slowly stood up and took out a small piece of paper, pen and gazed at his mother. Would you please name the items that I would write on this paper, I may not forget.

You will bring, Three kilos of some green beans, likewise bring six tins blended pickles, ten red and yellow peppers, a little pack of crisp apples, one container of moderate size tomatoes, a pot of chocolate hot espresso, five sorts of corn, some cookery book, a substantial group of bananas and spread, four containers of helpful new paste, some new extensive potatoes, twelve paper plates, yet keep in mind to bring entire Dover sole, six sorts of white early wine, a sack of dark colored flour, couple of olive oil and some cooking foil, a brew, not very dear, additionally add a few pears to share, ham to cure, yet in the event that you're certain for being immaculate, and a little piece of some Dutch cheddar, cut it thick or thin. Much obliged dear John.

The point of this examination study is to gauge the members' explanation of phonemes in consonants, particularly English dental fricatives sounds like/d/, /ब/ together with the English consistent noun plural suffixes, vowels and diphthongs. The above picked entry covers numerous English words containing phonemes of "th", noun plural forms along with words having vowels and diphthongs sounds in each line. This text essentially 
contains short expressions and little sentences rather than English words given in segregation. It is planned keeping in mind the end goal to elicit the participants' unconstrained and natural articulation. Along these lines, the words composed in the text are ordinarily utilized as a part of everyday discussion that the members can read the entry more effortlessly.

\subsection{Data Collection Procedure}

Data was collected from male participants. Every participant was exclusively given 15 minutes to familiarize himself and practice the entry with the assistance of an English dictionary, in order to help them understand the new words. Additionally, the participants were requested to articulate the text so that anyone can hear clearly at a typical speed with transitory stops between lines as necessary. Their readings of the writings were recorded by a high quality MP3 Player in a noiseless situation.

\subsection{Data Analysis}

The recorded information was transcribed through Praat software in order to recognize specific phonemic elements and methodical examples of their articulation in speech production. Later on, the recorded information was interpreted in tables. Two segments were created in each table: one segment exhibiting the actual articulation and the second section showing learner's way of articulation. Finally, the spectrograms were developed through Praat software in order to reveal the variation between actual articulation of English words and also to identify the incorrectly articulated words by the participants. The spectrograms are given below each table to illustrate the data more factually.

\section{Discussions and Findings}

\subsection{Consonants}

After examining the association of the recorded information, it was found that three differences took place with respect to consonant sounds. Three tables along with spectrograms by Praat software were devised to make the sound components more authentic and clear. Information of Table 1 reveals the participants' articulation of "th" sound at the primary position of a word. Table 2 demonstrates the participants' articulation of plural suffix like "s" and " $z$ " in the final position of English nouns. Table 3 demonstrates the diphthongization of English language by the participants (Table 1 and Figure 1, 2, 3, 4, 5, 6).

Table 1. Articulation of "th" at the initial position of a word

\begin{tabular}{|c|c|c|}
\hline Words & actual articulation & Participants articulation of English words \\
\hline These & $/ \mathrm{\partial I}_{\mathrm{I}} /$ & $/$ trez/ \\
\hline Things & /Өingz/ & $/ \operatorname{trng} /$ \\
\hline Three & /Өrr:/ & $/$ trr:/ \\
\hline Thick & $/ \Theta \mathrm{Ik} /$ & $/ \mathrm{trk} /$ \\
\hline Thin & $/ \theta \mathrm{in} /$ & $/ \mathrm{tm} /$ \\
\hline Thanks & /Өænks/ & /tænks/ \\
\hline
\end{tabular}

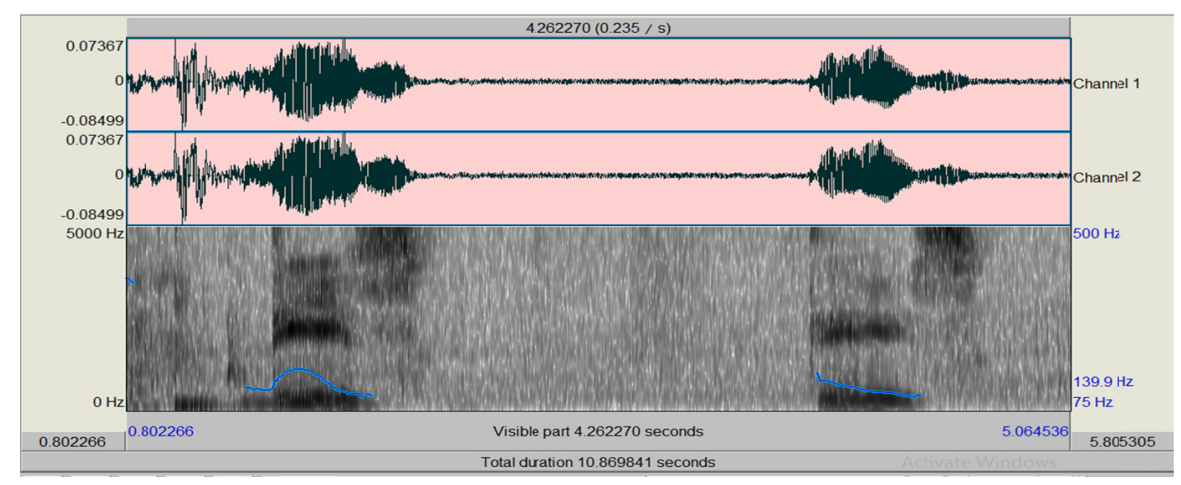

Figure 1. Articulation of English /ðı:z/ as /trez/ 


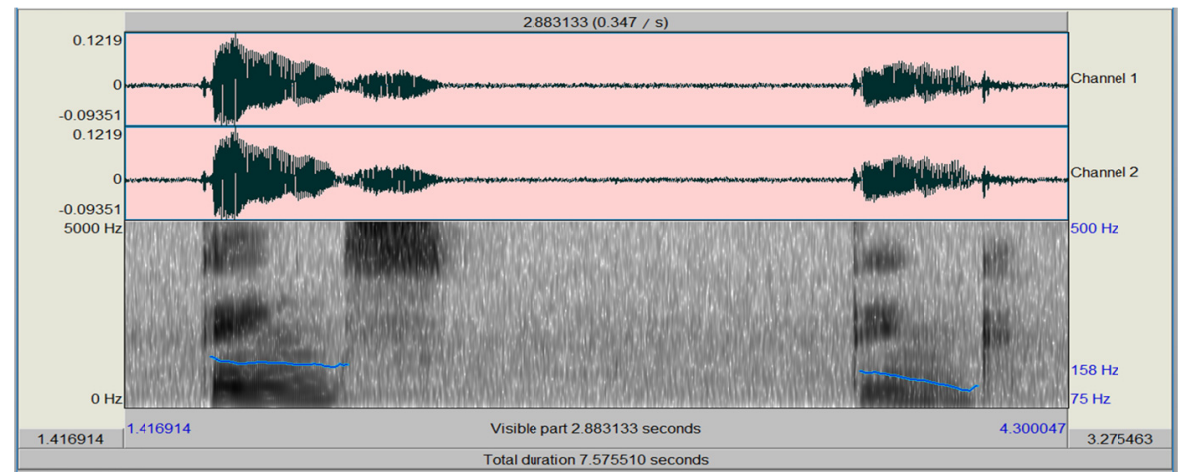

Figure 2. Articulation of/Өingz/ as /tins/

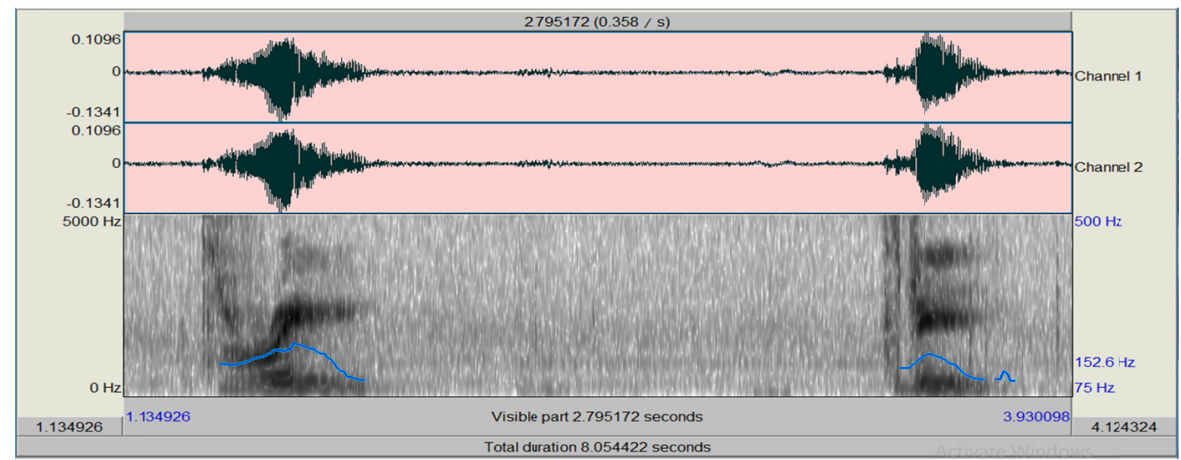

Figure 3. Articulation of /Өrr:/ as /trr:/

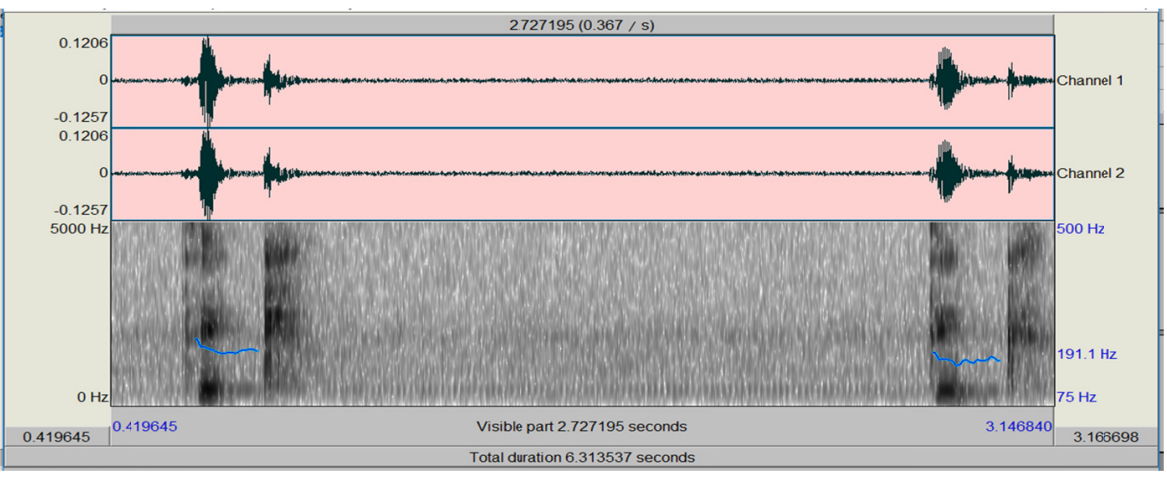

Figure 4. Articulation of / $/ \mathrm{ik} / \mathrm{as} / \mathrm{trk} /$

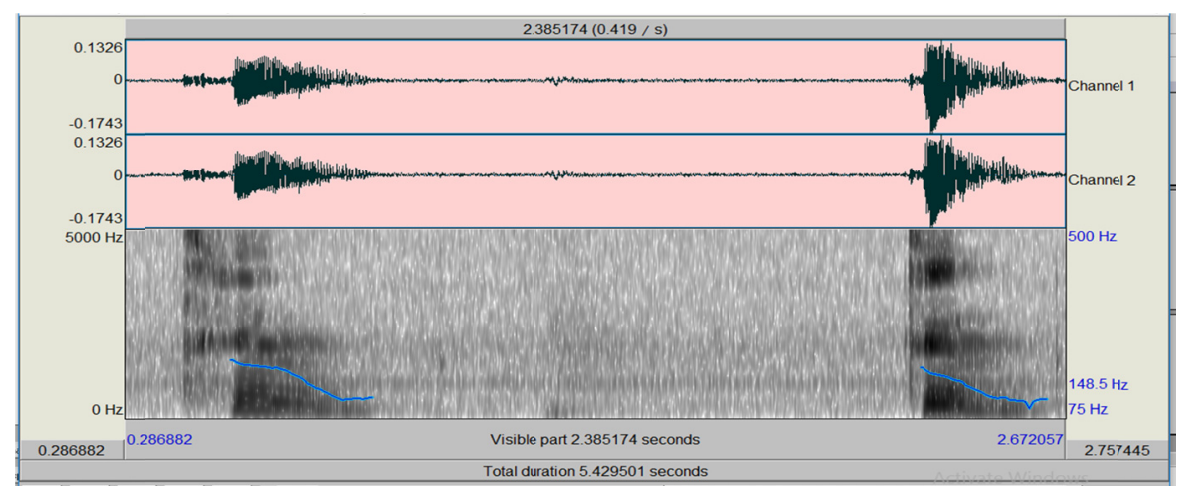

Figure 5. Articulation of / $/ \mathrm{m} / \mathrm{as} / \mathrm{tm} /$ 


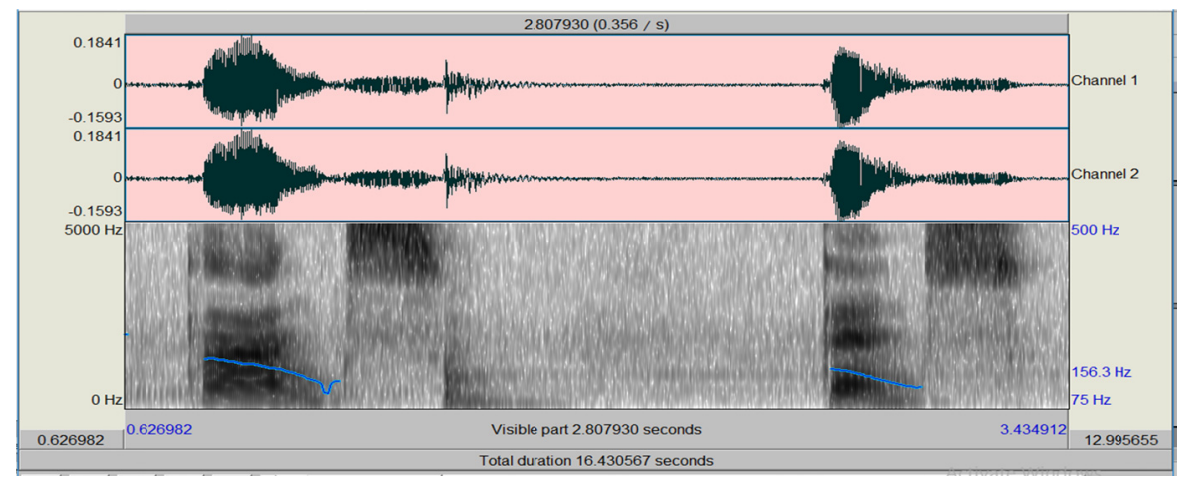

Figure 6. Articulation of /Өæทks/ as /tæyks/

It is clear from Table 1 and the six spectrograms that the participants faced problems in articulating these dental fricatives like $/ \delta /$ and $/ \Theta /$. These six English words, aside from the first that is "these," begin with the voiceless dental fricative $/ \Theta /$, the participants articulated them as voiceless alveolar as $/ t /$. Pashto speakers have a tendency to replace $/ \Theta /$ by $/ \mathrm{t} /$ as a substitution because $/ \Theta /$ sound in Pashto language is not accessible. That is the reason why they looked for alternative possible option during their sounds production. This phenomenon has been recognized by researchers in other languages, for instance Weinberger (1990), referred to in $\mathrm{Lu}$ (2008), contends that learners from different first language background can pick up a similar substitution and in their speech production, especially in Mandarin, Japanese, French, German etc. All learners of the second language substitute distinctive phonemes for $/ \Theta /$ sounds. All these five English words starting with /e/ sounds were produced by the participants as $/ \mathrm{t} /$. Along these lines, the deciphered information uncovered that the participants were not able to produce the targeted articulation of English words (Table 2, Figure 7 to 20).

Table 2. Articulation of regular plural suffixes

\begin{tabular}{|c|c|c|}
\hline \multirow{2}{*}{ Words } & \multirow{2}{*}{$\begin{array}{l}\text { Actual } \\
\text { Articulation of words }\end{array}$} & \multirow{2}{*}{$\begin{array}{l}\text { Participants' } \\
\text { Articulation of the words }\end{array}$} \\
\hline & & \\
\hline Things & /Oinz/ & /trins/ \\
\hline Kilos & /kıləuz/ & /kiləus/ \\
\hline Beans & /bi:nz/ & /bi:ns/ \\
\hline Tins & /tinz/ & /tins/ \\
\hline Pickles & /piklz/ & /prkls/ \\
\hline Peppers & /pepəz/ & /pepəs/ \\
\hline Apples & /æplz/ & /æpls/ \\
\hline Tomatoes & /təma:təuz/ & /təma:təus/ \\
\hline Bananas & /bəna:nəz/ & /bəna:nəs/ \\
\hline Tubes & /tju:bz/ & /tju:bs/ \\
\hline Pears & /peəz/ & /pıəs/ \\
\hline Potatoes & /pətertəuz/ & /patertəos/ \\
\hline Kinds & /kaindz/ & /karndz/ \\
\hline Sorts & /sc:ts/ & /sc:ts/ \\
\hline Plates & /pleits/ & /pleits/ \\
\hline
\end{tabular}




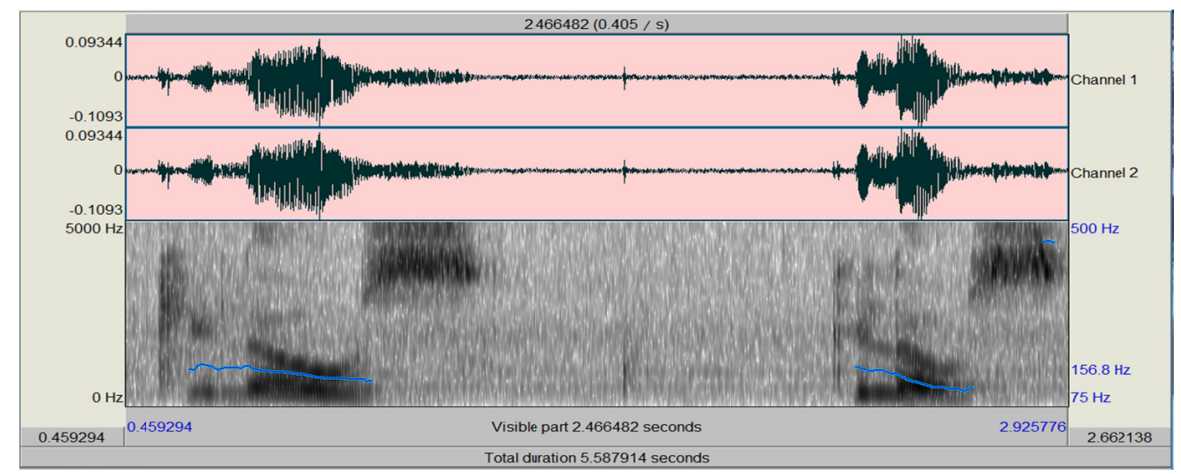

Figure 7. Articulation of English /kıləoz/ as /kıləus/

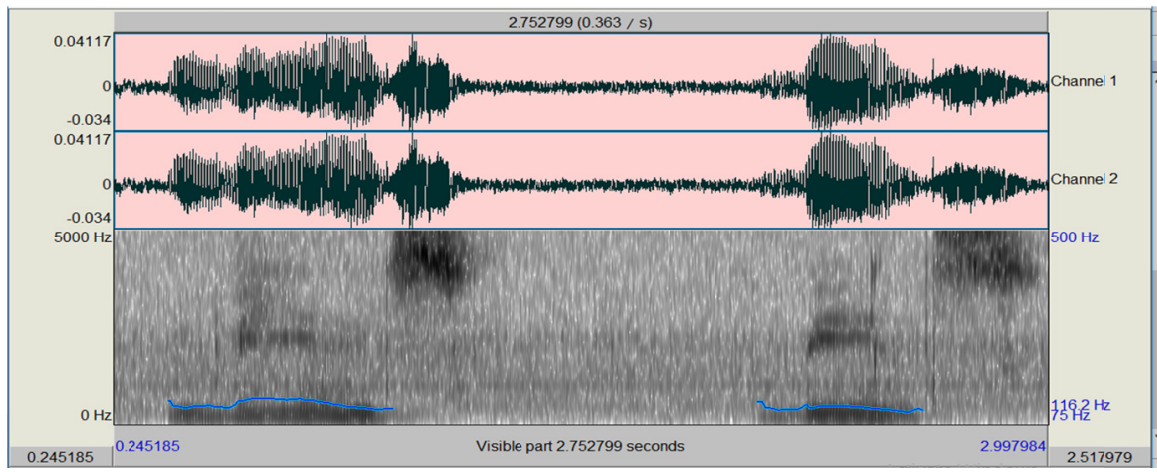

Figure 8. Articulation of English /bi:nz/ as /bi:ns/

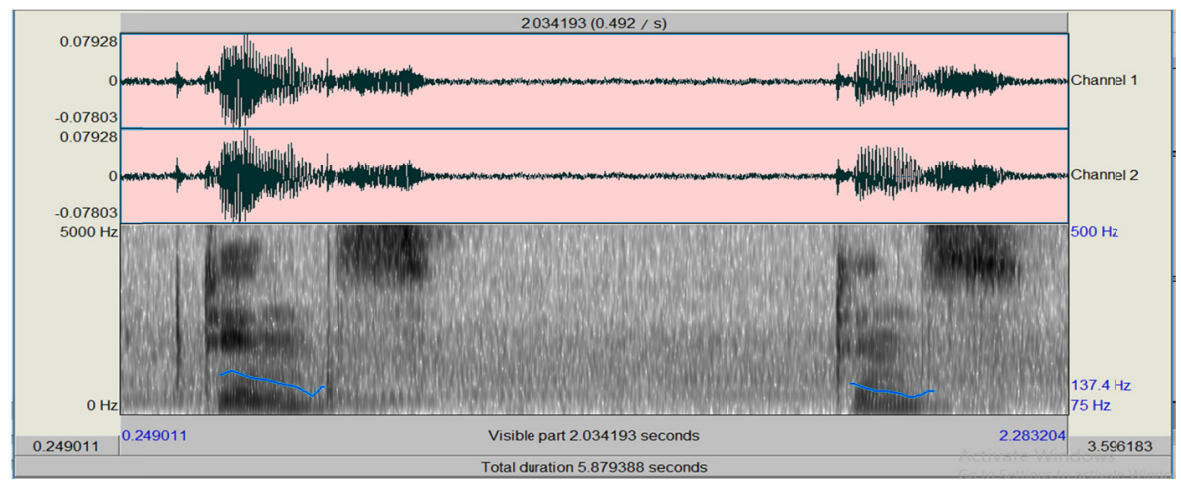

Figure 9. Articulation of /tmz/ as /tms/

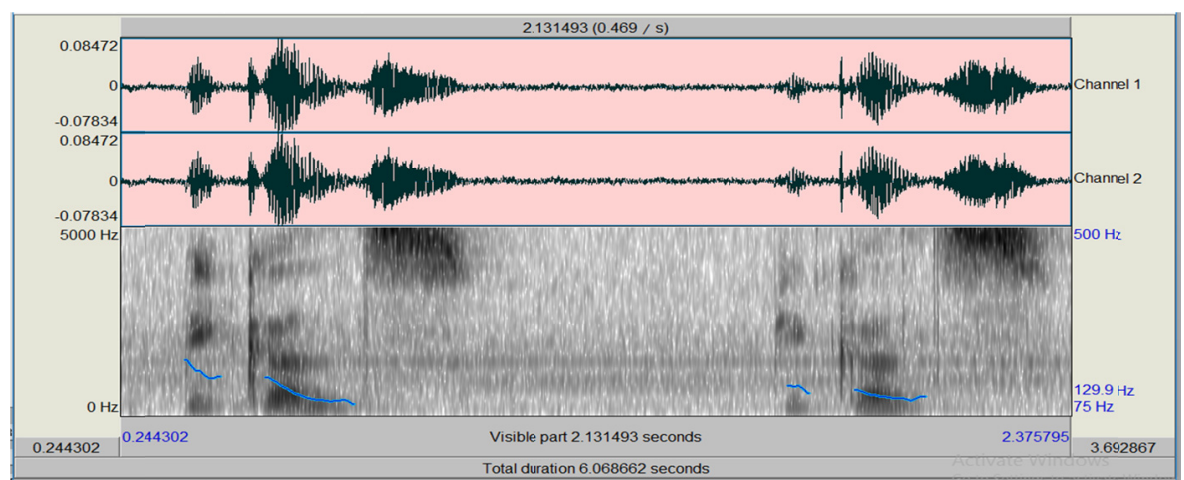

Figure 10. Articulation of English /prklz/ as /prkls/ 


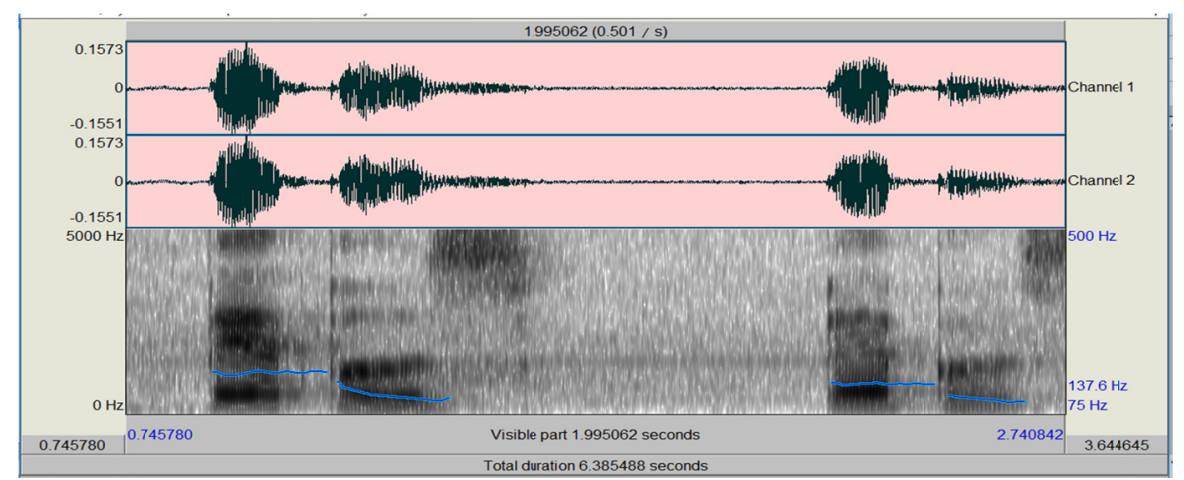

Figure 11. Articulation of English /pepəz/ as /pepəs/

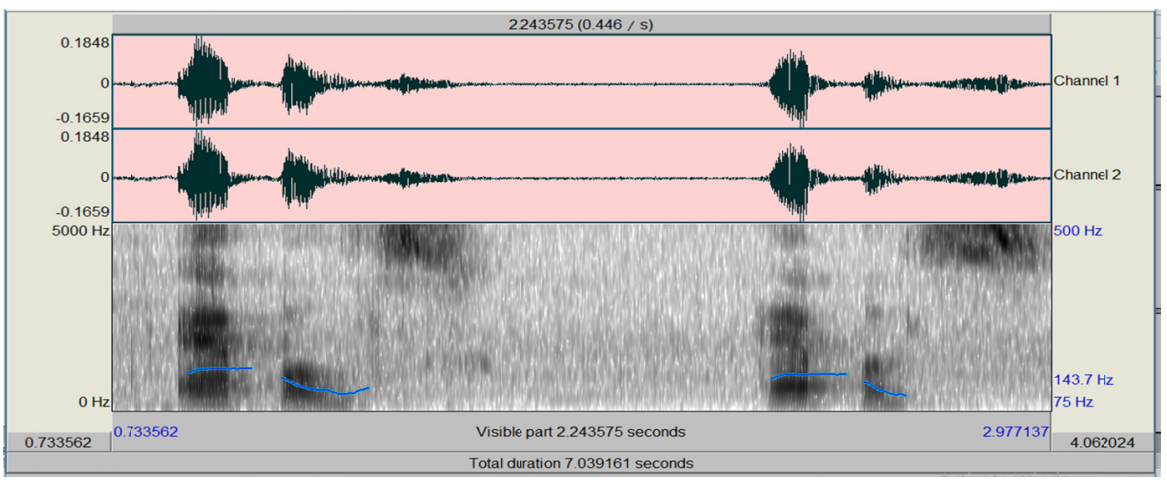

Figure 12. Articulation of /æplz/ as /æpls/

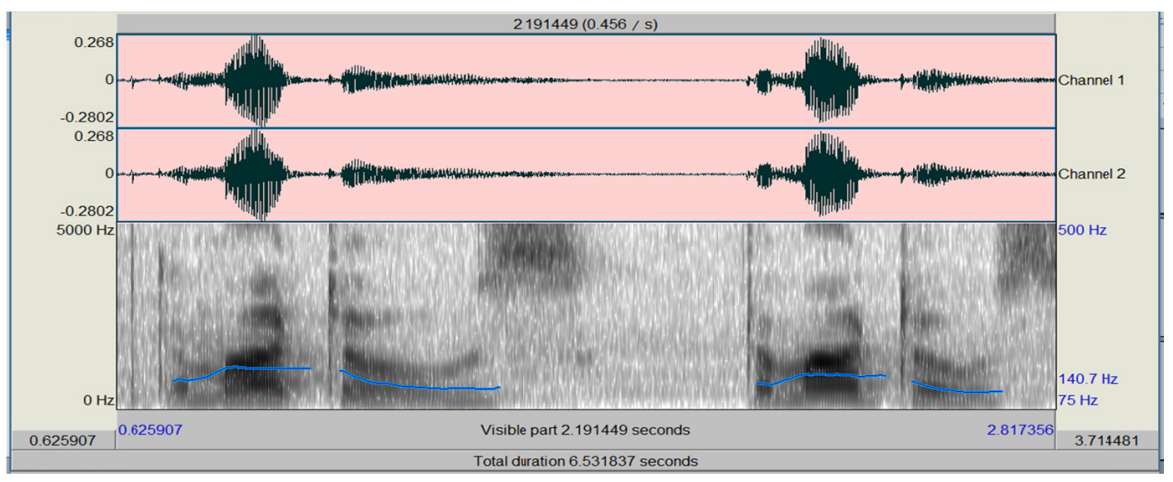

Figure 13. Articulation of /təma:təoz/ as /təma:təus/ 


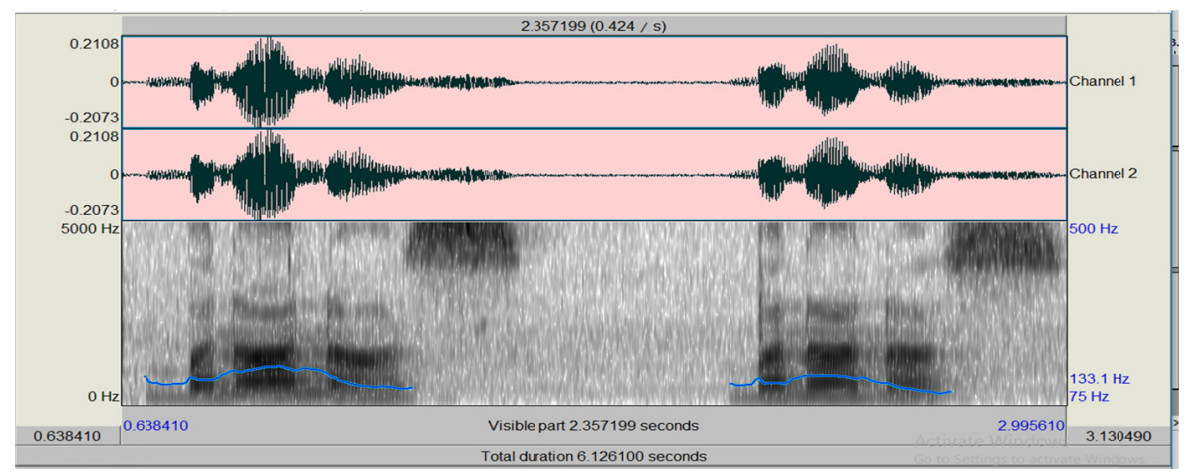

Figure 14. Articulation of English /bəna:nəz/ as /bəna:nəs/

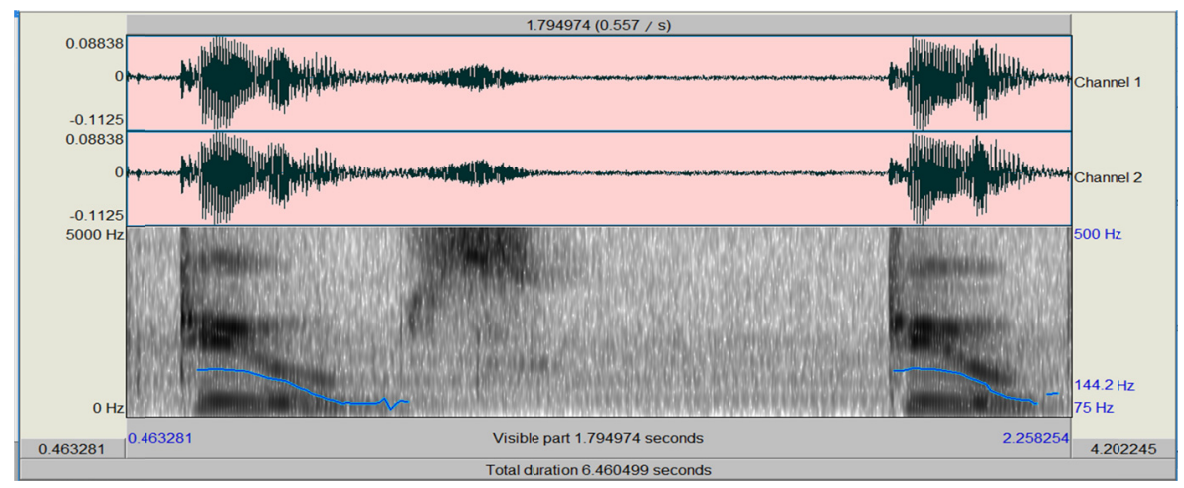

Figure 15. Articulation of /tju:bz/ as /tju:bs/

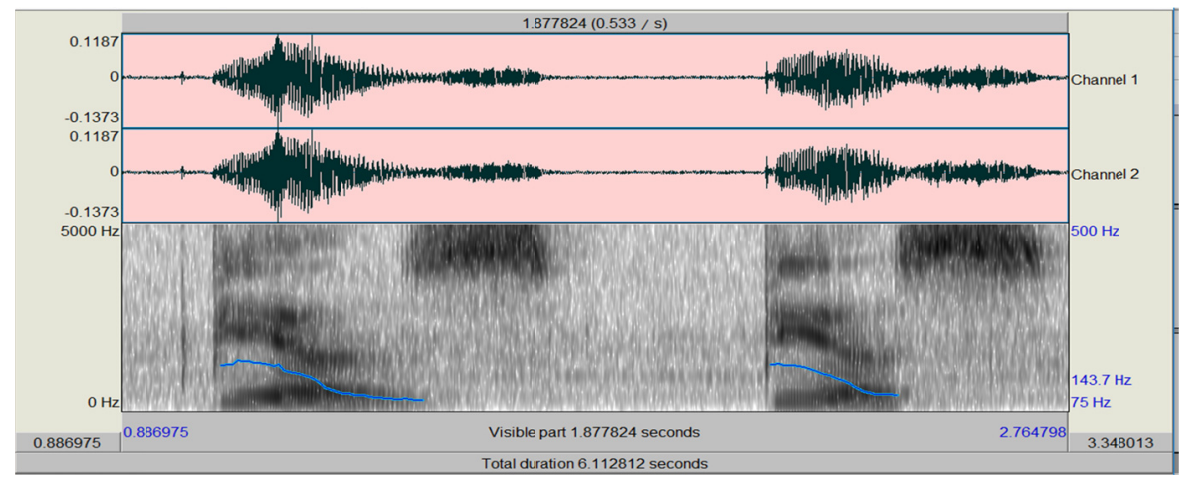

Figure 16. Articulation of /peəz/ as /prəs/ 


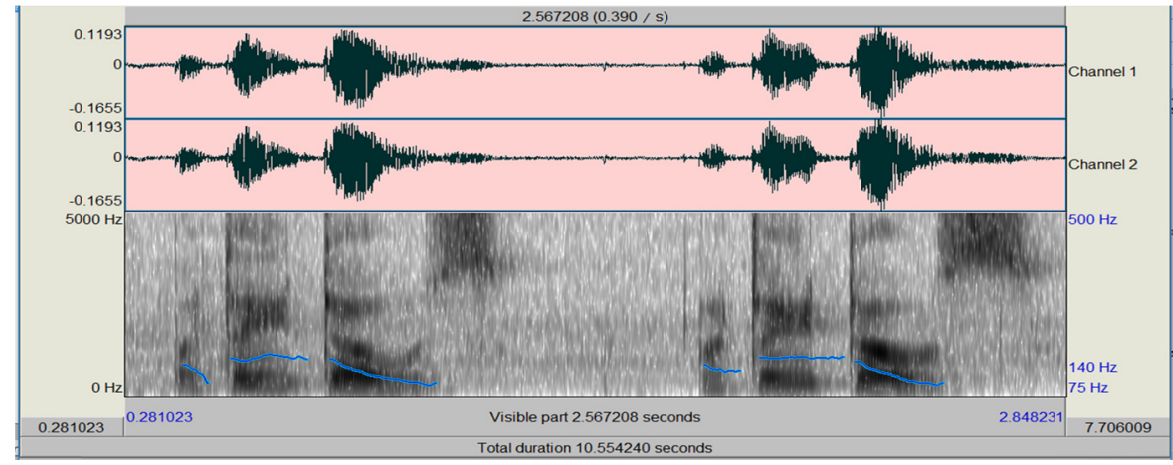

Figure 17. Articulation of /pətertəuz/ as /pətertəus/

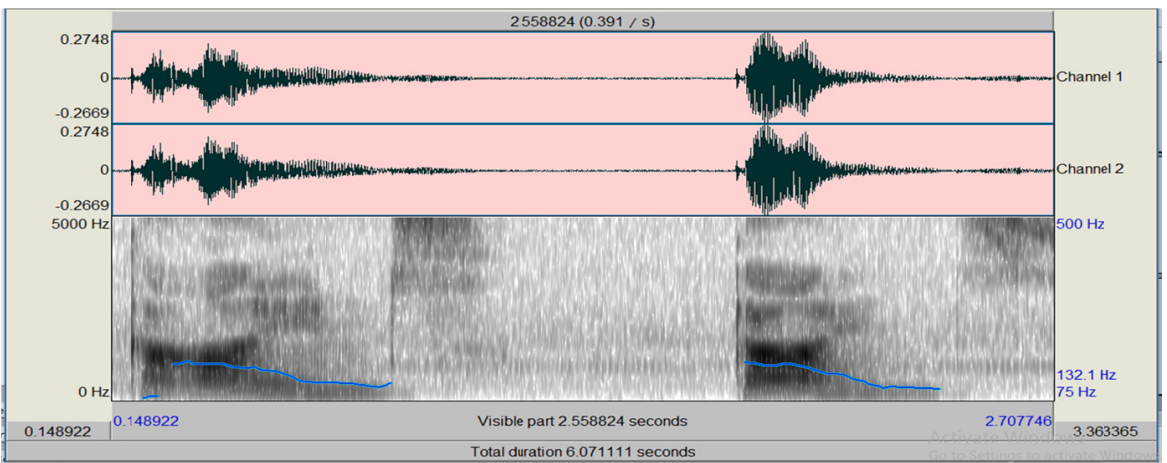

Figure 18. Articulation of /kaindz/ as /kaindz/

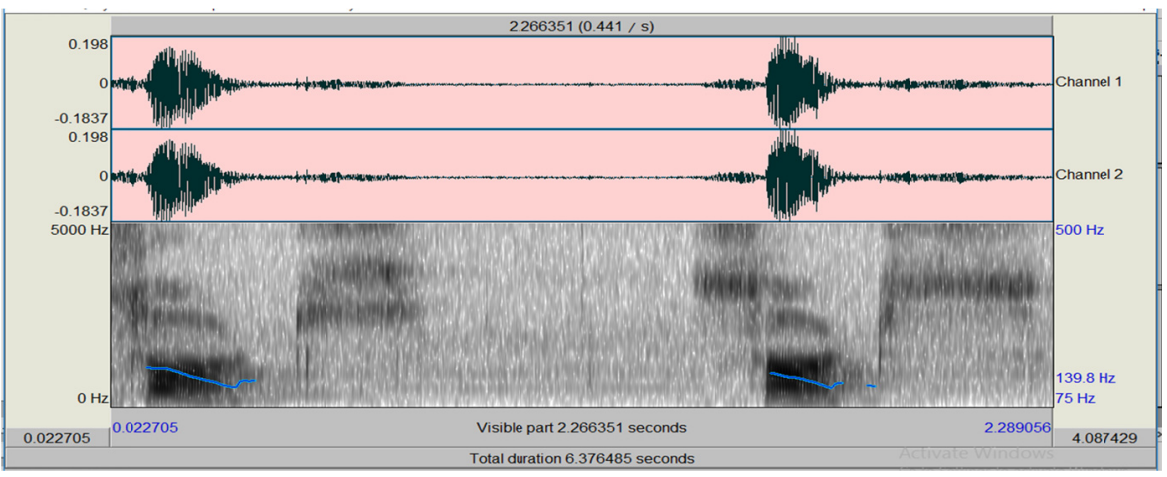

Figure 19. Articulation of /sc:ts/ as /sc:ts/

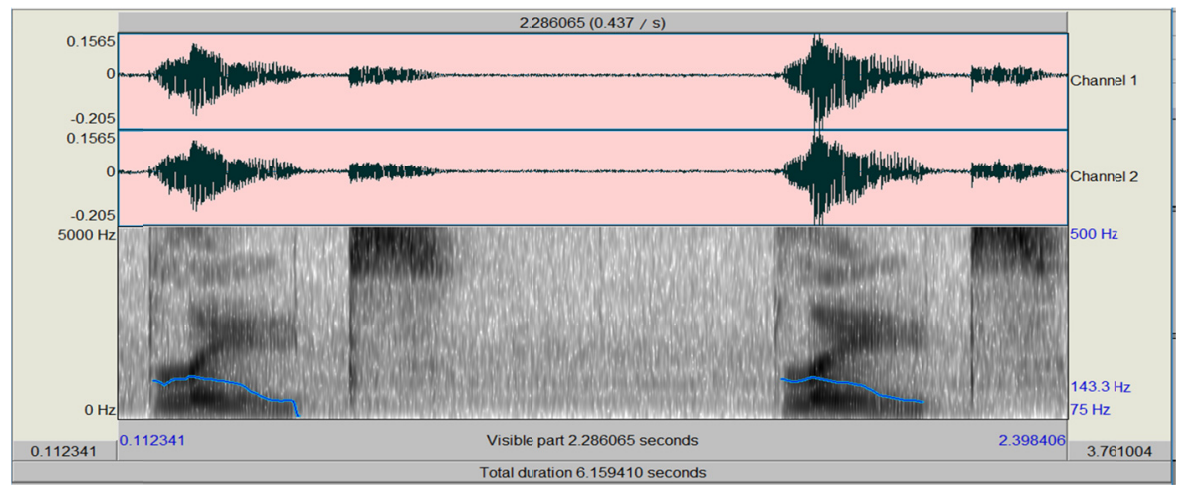

Figure 20. Articulation of /plerts/ as /plerts/ 
The voiced dental fricative phoneme of English language / $/$ /was produced as / $t /$ by the subjects. In this manner, there was just a single such word given in the included information. It is revealed that the participants were not able to articulate the targeted word. However, there can be some plausibility that they committed an inconsiderate error. Be that as it may, we can see from the collected data of articulation by the participants' sounds, including vowel /er/ and /i/ rather than /r:/ in this word "these". The sound /r:/ in English language is an unrounded front vowel, with the lips spread and it is regularly diphthongized by many second language learners (Cruttenden, 2001). So, the participants replaced /r:/ by /i/ and /ei/ with mouth more open than required, and this prompt phonetic setting causes the change of $/ \mathrm{d} / \mathrm{to} / \mathrm{t} /$ in their speech production.

The recorded information of Table 2 and Figure 7 to 20 revealed that the phonological components of the plural forms in English language create incredible trouble for the non-native speakers of English Language. The participants produced the postfixes of English lexeme plural form "s" as /s/ in their articulation of speech. These customary plural additions in English language take after different tenets (Avery \& Ehrlich, 2002; Deterding, \& Poedjosoedarmo, 1998). The principle decides and clarifies that if the last phoneme of the root form is one of the accompanying sounds $/ \mathrm{s}, \mathrm{z}, \int, 3, \mathfrak{t}$, dz/, the "s" postfix is articulated as /Iz/ or /əz/. The second principle states that if the last phoneme of the root form is not one of the sibilants and is voiced (all vowels are voiced), the "s" addition is to be articulated as $/ \mathrm{z} /$. The third principle decides that if the last phoneme of the root form is not a sibilant and is voiceless, the "s" postfix is to be articulated as "s". All the initial twelve words in Table 2 have a place in the second classification; however, the participants articulated all the postfixes as $/ \mathrm{s} /$, independent of any standards. Subsequently, it exhibits that their insight about the articulation of these consistent plural addition is that their continual inclusion of "s" implies pronouncing /s/. Aside from the plural form in their speech construction, they likewise articulated "please" /pli:z/ as /pl:s/ in their speech production. So, it is apparent from the collected information that their substitution of $/ \mathrm{s} /$ with $/ \mathrm{z} /$ is prevailing in their mother tongue or L1 (First Language), especially when the sound /s/ shows up at the coda position of English word. The last two words in Table 2 namely "sorts", and "plates" were altogether produced correctly by the participants. These two words share something alike in manner. These words wind up with the alveolar stop $/ \mathrm{t} /$ and $/ \mathrm{d} /$. Possibly, the participants can distinguish the postfix "s" rightly, when the last phoneme of the word is $/ \mathrm{t} / \mathrm{or} / \mathrm{d} / \mathrm{sound}$. (Table 3 , Figure 21 to 30 )

\subsection{Vowels}

Table 3. Vowel feature in the participants' articulation

\begin{tabular}{|c|c|c|}
\hline Words & Actual Articulation of the vowel in each Word & Participants' Articulation of the vowel in each word \\
\hline Three & /i:/ & $/ \mathrm{I} /$ \\
\hline These & /i:/ & /ei/ \\
\hline Kilos & $/ \mathrm{i} /$ & /ei/ \\
\hline Early & $/ \mathrm{i} /$ & /ei/ \\
\hline Ten & /e/ & $/ 2 /$ \\
\hline Few & /u:/ & /i:/ \\
\hline You & $\begin{array}{l}\text { Strong form } / \mathrm{u}: / \\
\text { weak form } / \mathrm{u} / \text { or } / \mathrm{a} /\end{array}$ & $/ \partial \mathrm{o} /$ \\
\hline Pound & /av/ & $/ \mathrm{p} /$ \\
\hline Brown & /av/ & $/ \mathfrak{p} /$ \\
\hline Pear & /ea/ & /10/ \\
\hline Share & /ea/ & /19/ \\
\hline
\end{tabular}

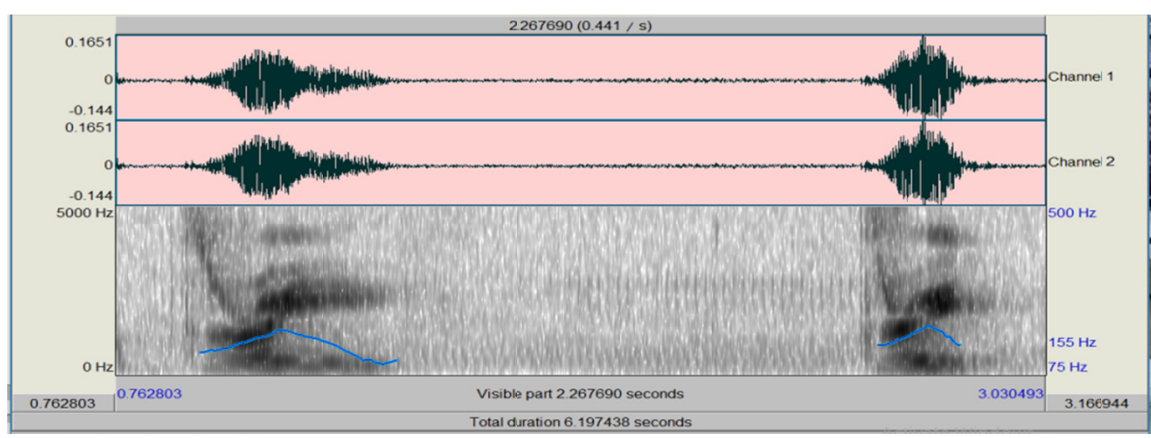

Figure 21. Articulation of English /i:/ as /I/ 


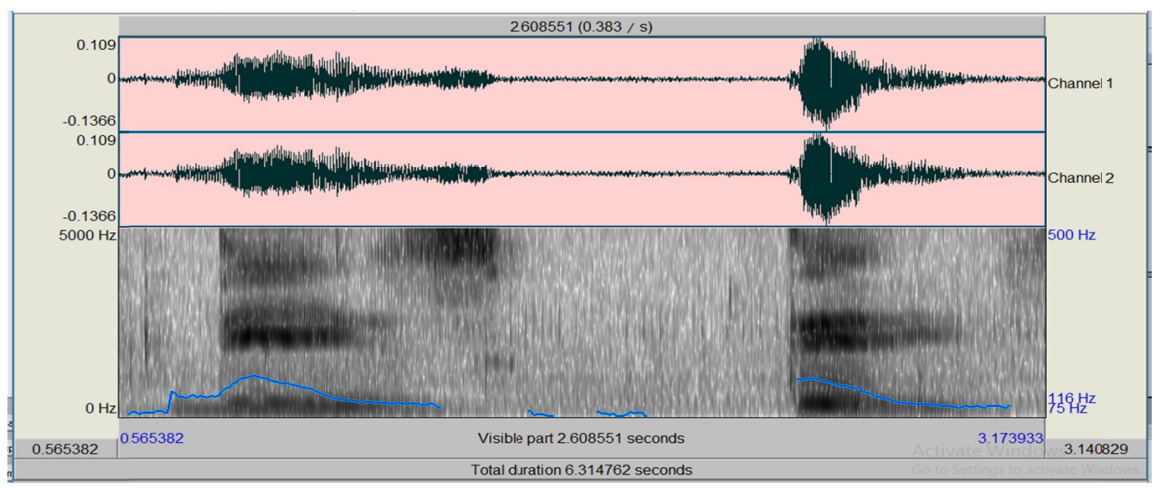

Figure 22. Articulation of English /i:/ as /eI/

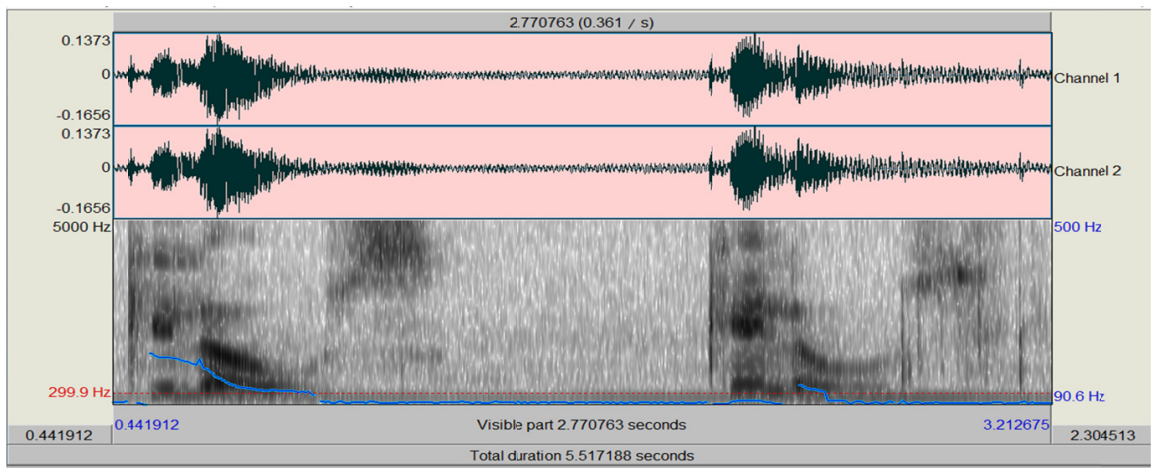

Figure 23. Articulation of /i/ as /er/

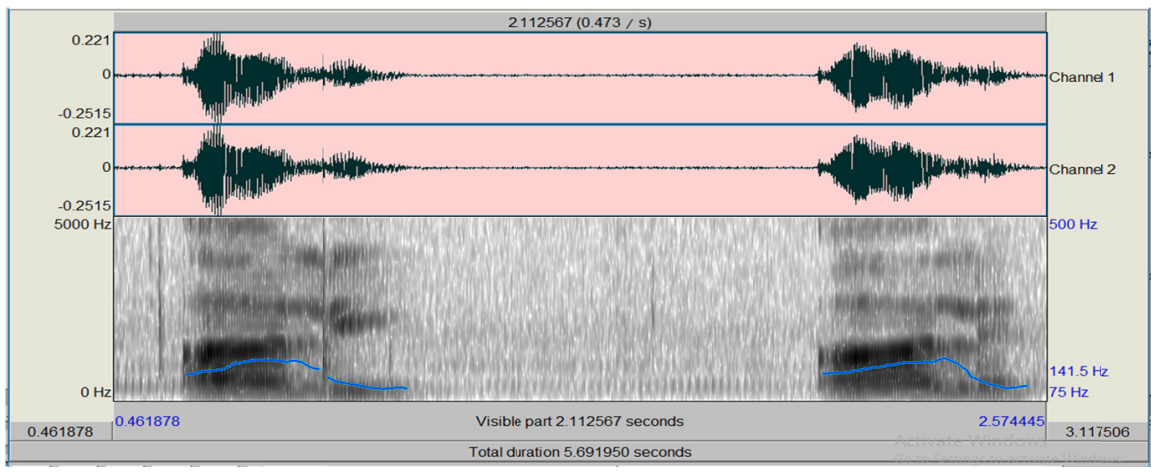

Figure 24. Articulation of English /i/ as /ei/

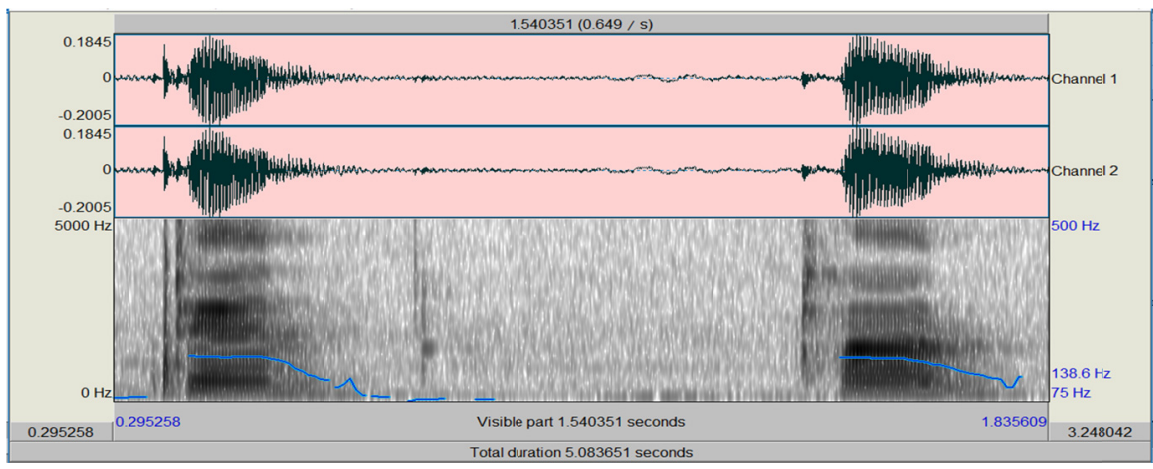

Figure 25. Articulation of English /e/ as /a/ 


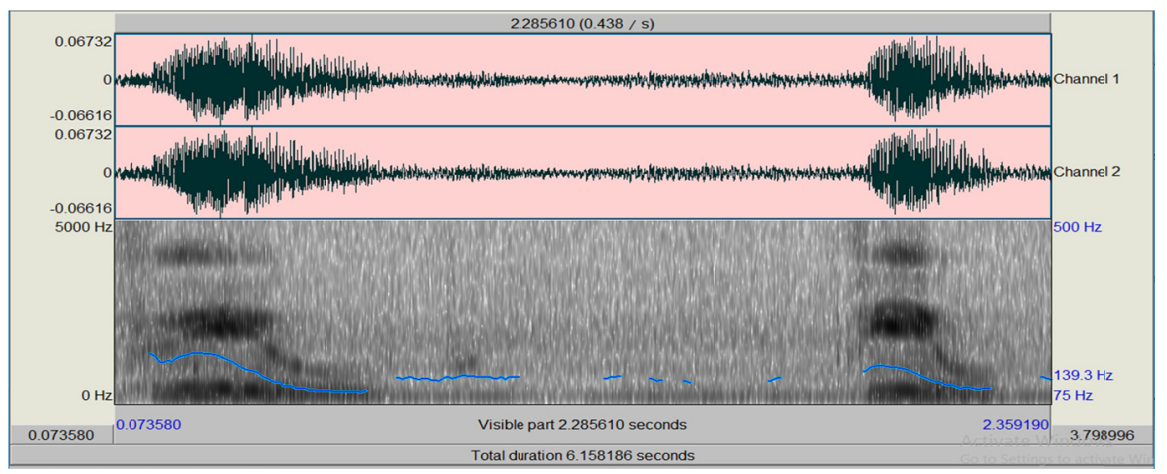

Figure 26. Articulation of English /u:/ as /i:/

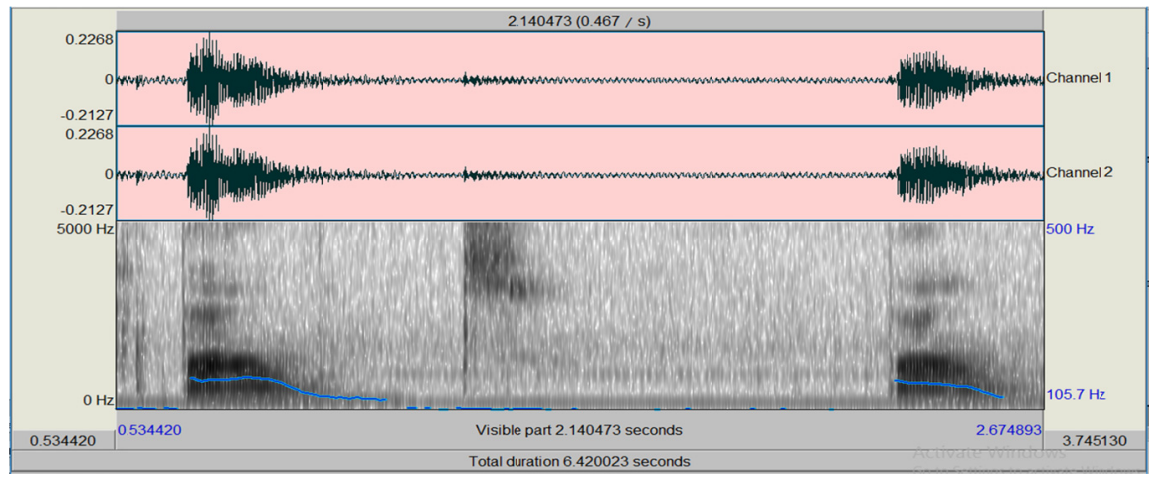

Figure 27. Articulation of English /av/ as / $/$ /

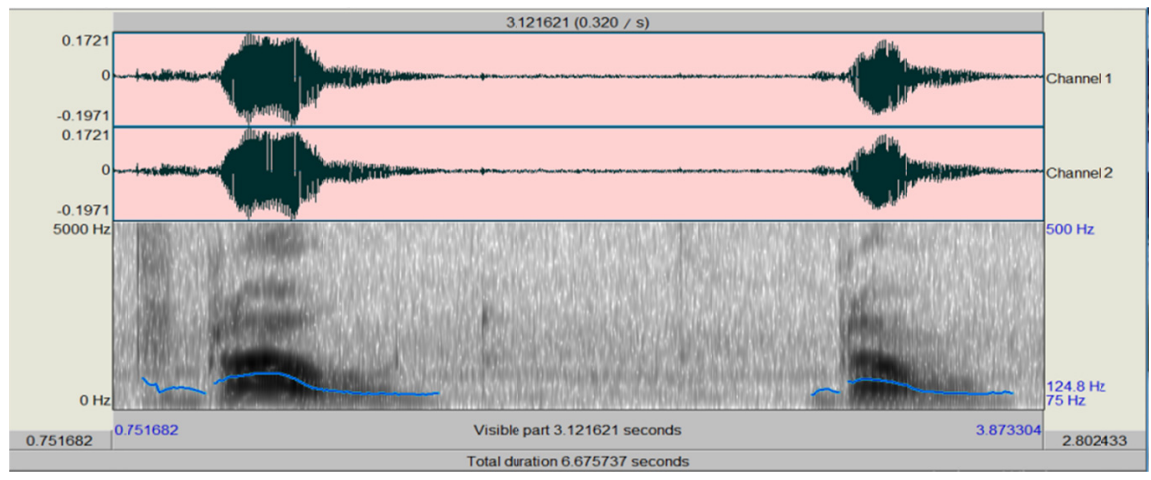

Figure 28. Articulation of English /av/ as /p/

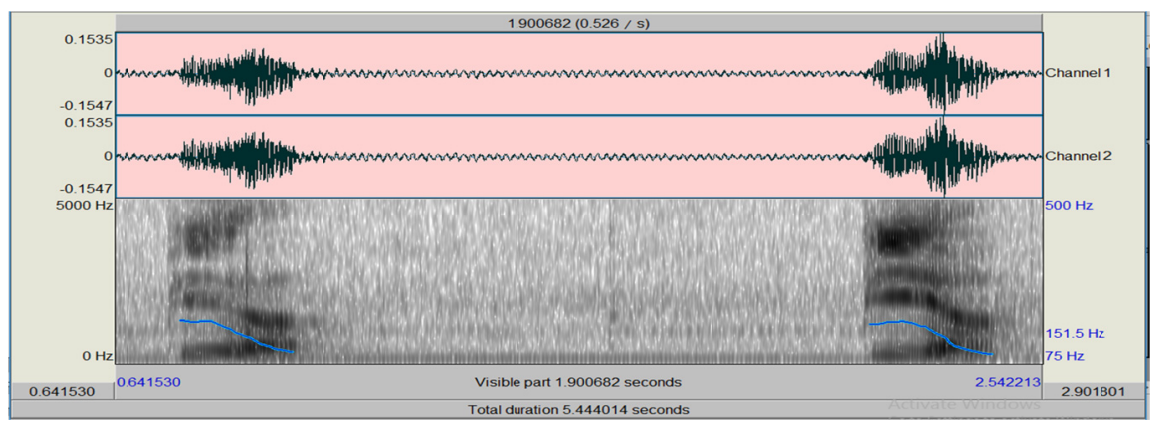

Figure 29. Articulation of English /eə/ as /ıə/ 


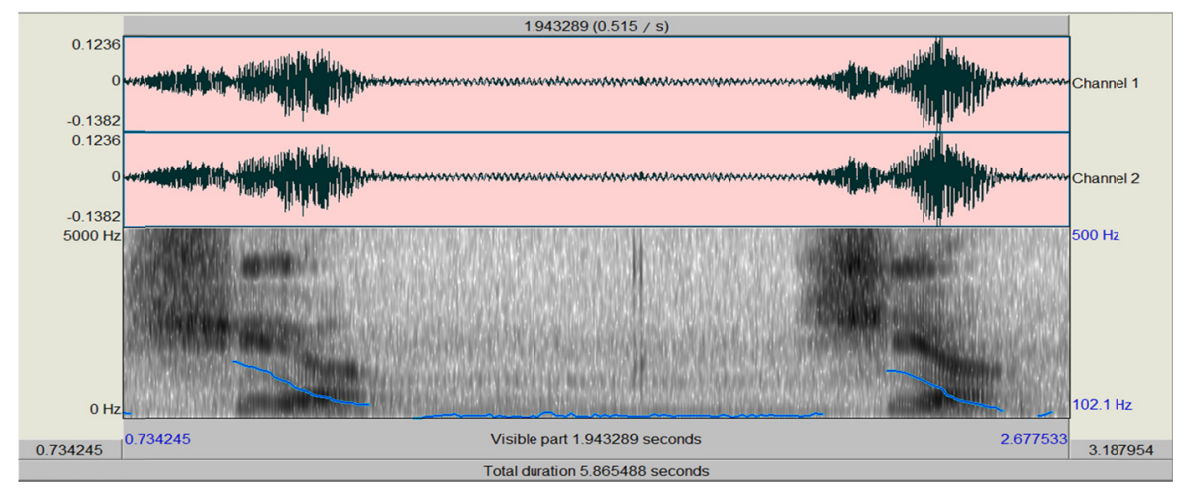

Figure 30. Articulation of English /ea/ as /ı/

The consonants, vowels and diphthongs were demonstrated in Table 1 and Table 2 along with spectrograms and with specified example of articulation in speech sounds. In Table 3, we can see that there are few vowels and diphthongs in English RP dialect that were inaccurately produced by the participants, for instance, /i:/ is replaced by $/ \mathrm{I} /$. The participants for a number of times misarticulated sounds, such as, $/ \mathrm{a}: /, / \Lambda /, / \mathrm{p} /$, and $/$ eə $/$.

The articulation of the sounds produced by participants with reference to vowels and diphthongs are abridged and analyzed as: First of all, the vowel sounds including diphthongs which they produced were /av/ and /eə/ as $/ \mathfrak{p} /$ and even produced like /ro/. In general, they confronted more noteworthy trouble in articulating these English diphthongs contrasted with mono-thongs. Also, there was a captivating result of the recorded information that a higher rate of incorrect articulation of /i:/ and /i/ as /ei/ and /i/ revealed their way of speaking English Language. This phenomenon can be attributed to the solid emphasis of Pashto language on /er/ and /i/. That is the reason why the participants from Pashto vernacular contrarily influence their act of locating the diphthong. Thirdly, they articulated /u:/ as /i:/ in "few" and /əo/ in the word "you". However, /e/ is also difficult for Pashto speakers to recognize, for instance, "red" in the entry. In any case, the participants committed errors concerning the correlation of these two sounds. They articulated /ten/ as /tən/. Overall, the participants' articulation of vowels and diphthongs sounds showed that they face issues in their pronunciation of English language in these sounds.

\section{Conclusion}

The above articulation by the participants revealed that Pashto speakers confront more noteworthy issues in the production of dental fricative sounds and customary plural structures. They produced voiceless dental fricative $/ \Theta /$ as $/ \mathrm{t} /$ when $/ \Theta /$ happens at the word primary position. Evidence has been found about their inclination in the production of $/ \delta /$ speech sound in the word-starting position. Their most serious issues happened in the articulation of customary plural postfixes. They generally indiscriminately connected the third principle to most plural types of lexeme and articulated it as $/ \mathrm{s} /$. As far as vowel sounds and diphthongs are concerned, issues predominantly showed up in perplexity between /i:/,/I/ and /ei:/ and /av/, /ea/. These sounds were very difficult for the subjects to articulate. The substitution of $/ \mathrm{t} /$ for $/ \Theta /$ is middling for Pashto speakers from Khyber Pakhtunkhwa, Pakistan. Despite the fact that the component with respect to vowels sounds and diphthongs were not that precise and did not take after specific example like consonants, the examination of the collected data additionally showed that they have more serious issues in the production of these sounds specially in /i:/, /i/, /e/, /u:/, /av/ and /eə/.

Excessive consideration ought to be paid to the consonants, vowels and diphthongs by the English language educators, when teaching speech sounds. In the meantime, the teachers ought to likewise raise their mindfulness about learning English sounds and attempt their level best to enhance their English vernacular explanation, with a specific end goal to communicate in English language easily.

\section{References}

Avery, P., \& Ehrilich, S. (2002). Teaching American English pronunciation. Oxford: Oxford University Press.

Bernard, C. (1990). The major languages of the middle east and Africa. London: Rutledge.

Bukhari, N., \& Ataleeq, K. (1984). Pashto. De chapazay, Peshawar.

Cruttenden, A. (2001). Gimson's articulation of English. London: Arnold.

Davenport, M., \& Hannahs, S. J. (2005). Introducing phonetics and phonology. London: Hodder Arnold. 
Deterding, D., \& Poedjosoedarmo, G. (1998). The sounds of English: Phonetics and phonology for English teachers in Southeast Asia. Upper Saddle River, NJ: Prentice Hall.

Elkhair, M. I. H. (2014). Pronunciation Problems: A Case Study of English Language Students at Sudan University of Science and Technology. English Language and Literature Studies, 4. Canadian Center of Science and Education

Elmahdi, O. E. H., \& Khan, W. A. (2015). The pronunciation problems faced by Saudi EFL learners at secondary schools. Education and Linguistics Research, 1(2), 85.

Herbert, P. (1955). A grammar of Pashto. Washington, DC: American Council of Learned Societies.

Jia, G., Strange, W., Wu, Y. H., Collado, J., \& Guan, Q. (2006). Perception and production of English vowels by Mandarin speakers: Age-related differences vary with amount of L2 exposure. Acoustical Society of America, 119(2), 1118-1130. https://doi.org/10.1121/1.2151806

Joan, B., \& Esther, B. L. (2001). Bibliography of languages of northern Pakistan. NIPS/SIL.

Khan, K. (1990). Pashto Urdu Lughat. Pashto Academy University of Peshawar.

Ladefoged, P., \& Ian, M. (1996). The sounds of the world languages. Massachusetts, USA: Blackwell publishers Inc.

Lado, R. (1964). Linguistics cross-cultures: Applied linguistics for language teachers. Ann Arbor: The University of Michigan Press.

Liu, J., Tindall, E., \& Nisbet, D. (2006). Chinese learners and English plural forms. The Linguistics Journal, 1(3), 127-147.

Lu, Y. A. (2008). Adaptation of English interdental fricatives by speakers of Taiwan Mandarin. Paper presented at 18th International Congress of Linguists (CIL 18), Korea University. Retrieved from http://www.nyu.edu/gsas/dept/ lingu/

Majeed., \& Abdul, M. S. (1992) . Lisaniyat-e- Pakistan. Muqtadra qaumi zuban, Islamabad.

Massica \& Collin, P. (1991). The Indo-Aryan Languages. Cambridge: Cambridge University Press.

Menyuk, P. (1968). The role of distinctive features in children's acquisition of phonology. Journal of Speech and Hearing Research, 11, 138-146. https://doi.org/10.1044/jshr.1101.138

Michael, H. (1983). Four varieties of Pashto. Journal of the American Oriental Society, 103, 595-598. https://doi.org/10.2307/602038

Pickett, J. M. (1888). The Acoustics Darmesteter, James. Chants populaires des afghans. Paris: Klincksieck.

Roach, P. (2000). English Phonetics and Phonology. London: Cambridge University Press.

Schmidt, R. (1977). Sociolinguistic variation and language transfer in phonology. Retrieved from http://eric.ed.gov/ ERICDocs/data/

Wang, X. C. (1997). The acquisition of English vowels by Mandarin ESL learners: A study of production and perception (Unpublished master's thesis). Simon Fraser University, Canada.

Yang, C., Robb, M., Gilbert, H., \& Lerman, J. (2001). Vowel production by Mandarin speakers of English. Clinical Linguistics \& Phonetics, 15(6), 427-440. https://doi.org/10.1080/02699200110044804

\section{Copyrights}

Copyright for this article is retained by the author(s), with first publication rights granted to the journal.

This is an open-access article distributed under the terms and conditions of the Creative Commons Attribution license (http://creativecommons.org/licenses/by/4.0/). 